\title{
Plaque Vulnerability in Internal Carotid Arteries with Positive Remodeling
}

\author{
Toshiyasu Miura $^{a}$ Noriyuki Matsukawa ${ }^{a}$ Keita Sakurai ${ }^{b}$ \\ Hiroyuki Katano ${ }^{c}$ Yoshino Ueki $^{a}$ Kenji Okita $^{a}$ Kazuo Yamadac \\ Kosei Ojika ${ }^{a}$
}

Departments of a Neurology, ${ }^{b}$ Radiology and ${ }^{\mathrm{C}}$ Neurosurgery, Nagoya City University, Nagoya, Japan

\section{Key Words}

Black-blood magnetic resonance image $\cdot$ Carotid artery $\cdot$ Multidetector-row computer tomography $\cdot$ Plaque vulnerability $\cdot$ Positive remodeling

\begin{abstract}
Background: This study aimed to evaluate the efficacy of assessing positive remodeling for predicting future stroke events in the internal carotid artery. We therefore assessed narrowing of the carotid artery lumen using multidetector-row computer tomography (MDCT) angiography and carotid plaque characteristics using black-blood (BB) magnetic resonance (MR). Methods: We retrospectively selected 17 symptomatic and 11 asymptomatic lesions with luminal narrowing $>50 \%$. We compared remodeling parameters of luminal stenosis (remodeling ratio, RR/remodeling index, RI) using MDCT and MR intensities of atherosclerotic plaque contents using the $\mathrm{BB}$ technique (relative signal intensity, $\mathrm{rSI}$ ). We also confirmed the validity of the relationship between MR intensity and atherosclerotic plaque contents by histology. The levels of biological markers related to vessel atherosclerosis were measured. Results: Plaque lesions with positive remodeling in carotid arteries were associated with a significantly higher prevalence of stroke compared with plaques with negative remodeling $(p<0.05)$. Radiologic and histologic analyses determined that plaques with positive remodeling had higher signal intensities (with respect to their lipid-rich content or to hemorrhage) compared with negative remodeling (correlation coefficients: $\mathrm{RI}$ and $r \mathrm{SI}, r=0.41, p<0.05 ; \mathrm{RR}$ and $r \mathrm{SI}, r=0.50, p<0.05$ ). Levels of biological markers, including high-sensitivity C-reactive protein, hemoglobin A1C, total cholesterol, low-density lipoprotein cholesterol and high-density lipoprotein cholesterol, were not useful for predicting stroke events. Conclusions: The results of this study suggest that the combined analysis of RR, $\mathrm{RI}$ and $\mathrm{rSI}$ could potentially help to predict future stroke events.

Copyright $\odot 2011$ S. Karger AG, Basel
\end{abstract}




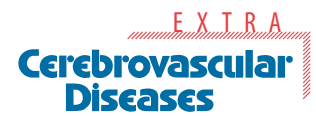

Discases
Cerebrovasc Dis Extra 2011;1:54-65

DOI: $10.1159 / 000328645$

Published online: May 31, 2011

Miura et al.: Positive Remodeling in the Carotid Artery
๔ 2011 S. Karger AG, Basel

www.karger.com/cee

\section{Introduction}

The formation of atherosclerotic plaques in the extracranial internal carotid arteries is a common cause of cerebrovascular disease. Carotid endarterectomy (CEA) and carotid arterial stenting (CAS) can be useful interventions for preventing secondary strokes in patients unresponsive to medical therapy. The decision to perform interventional therapies is currently based on the percent luminal narrowing of the vessel [1-3]. However, some patients with minimal stenosis in extracranial internal carotid arteries can unexpectedly experience strokes related to the rupture of atherosclerotic plaques, whereas other patients with severe stenosis remain stroke free. Better methods of distinguishing between these patients are needed to decide on the optimal treatment, i.e. CEA or CAS, versus medical therapy.

Several recent studies have indicated that coronary arteries may respond to plaque growth in two different ways: either by outward expansion of the vessel wall (positive remodeling) or by vessel shrinkage (negative remodeling) [4]. In coronary events, positive remodeling may be associated with an unstable clinical presentation, whereas negative remodeling may be more common in patients with stable clinical presentations [5]. Coronary artery plaques with positive remodeling have also been shown histologically to have a higher lipid content and macrophage count [6]. The vulnerability of an atherosclerotic plaque to rupture is considered to be related to its intrinsic composition, including the size of the lipid core and the presence of intraplaque hemorrhage [7]. Indeed, the characteristics of atherosclerotic plaques were shown to strongly correlate with the prevalence of coronary events in patients with coronary stenosis caused by atherosclerotic plaques [8].

A previous report suggested that the extent of expansive remodeling may also indicate underlying atherosclerotic plaque vulnerability in internal carotid artery stenosis [9]. This report assessed the remodeling ratio (RR, i.e. the ratio of outside vessel circumference between the point of maximal luminal stenosis and the unaffected region) and investigated the correlation between this ratio and the prevalence of stroke. However, the role of the qualitative histologic characteristics of carotid artery atherosclerotic plaques in plaque vulnerability remains unknown.

Multidetector-row computer tomography (MDCT) angiography is a powerful, noninvasive tool for rapidly assessing the percent luminal narrowing in carotid arteries. Although it may be inferior to magnetic resonance imaging (MRI) for determining the histologic characteristics of plaques, MDCT has been reported to be able to differentiate between internal plaque components [10].

However, the combination of spin echo-based $\mathrm{T}_{1^{-}}, \mathrm{T}_{2^{-}}$and intermediate-weighted imaging and of $\mathrm{T}_{2}{ }^{*}$-weighted gradient recall echo in MRI was reported to be useful for evaluating individual histologic plaque components $[11,12]$. Recent studies demonstrated the use of pulse sequences designed for vascular imaging, namely black-blood (BB) techniques [13, 14]. However, these $\mathrm{BB}$ techniques are based on the acquisition of two-dimensional data with a section thickness of $2-5 \mathrm{~mm}$, making it difficult to capture the whole picture and determine the maximal percent luminal narrowing in carotid arteries.

This study aimed to elucidate the association between carotid artery positive remodeling and the risk of incident stroke using a combination of MDCT angiography and noninvasive MR characterization. We confirmed that histologic classification by MRI matched plaque characterization. We designed a retrospective study to assess carotid artery luminal narrowing using MDCT angiography and carotid plaque characteristics using the BB MR technique. The reliability of the results was confirmed by direct comparison of some carotid plaques obtained by CEA with the results of BB MRI. 


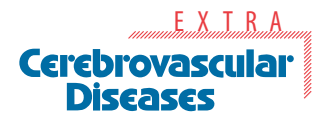

\begin{tabular}{l}
\hline \begin{tabular}{l}
\hline Cerebrovasc Dis Extra 2011;1:54-65 \\
\hline DOI: 10.1159/000328645
\end{tabular} \\
$\begin{array}{ll}\text { Published online: May 31, 2011 } 2011 \text { S. Karger AG, Basel } \\
\text { www.karger.com/cee }\end{array}$ \\
\hline
\end{tabular}

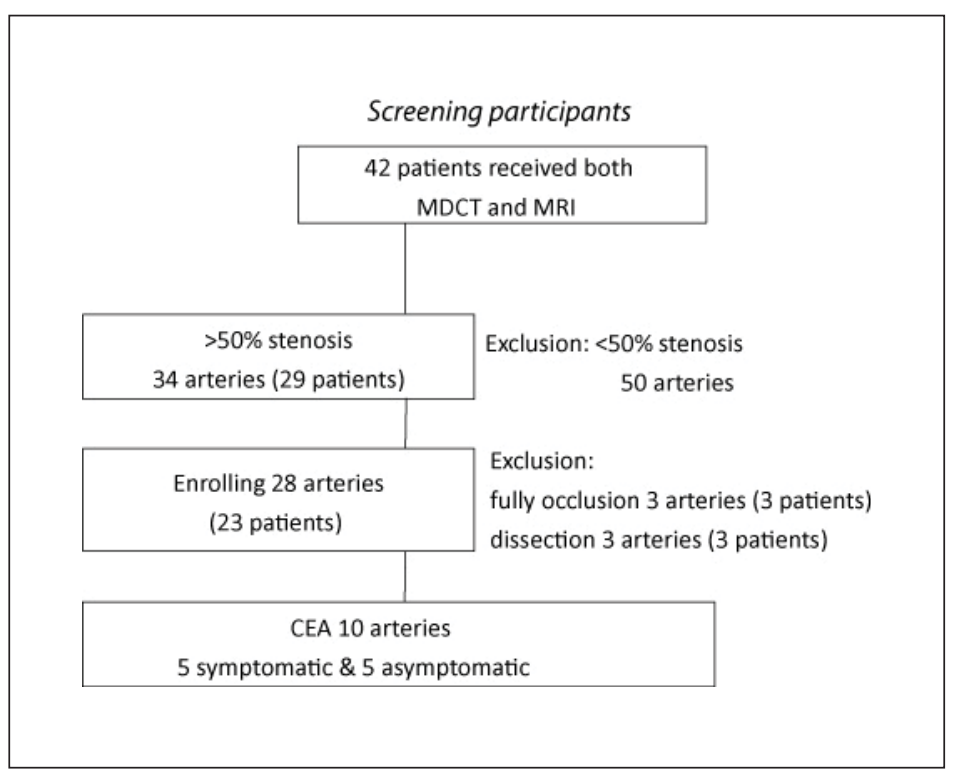

Fig. 1. Patient screening. Forty-two participants who underwent both MDCT angiography and BB MR analysis were identified in the Nagoya City University Medical Center database from August 2008 to July 2010; 50 arteries were excluded because of stenosis $<50 \%$ in NASCET, and 6 arteries were excluded because of the presence of other potential causes of neurologic symptoms (full occlusion, 3 arteries, and possible dissection, 3 arteries). Twenty-eight arteries were finally enrolled in this study; 10 of the 28 were treated surgically (CEA).

\section{Subjects and Methods}

This study was approved by the Medical Ethics Committee of the Nagoya City University Graduate School of Medical Sciences. Informed patient consent was not required.

\section{Patient Population}

The study group was selected following a search of the patient database of the Nagoya City University Medical Center from August 2008 to July 2010. Patient backgrounds were standardized by applying the following inclusion criteria: (1) received both dedicated MDCT angiography and BB MR analysis of the neck using the same imaging parameters, and (2) neuroradiologic verification by a neurologist. During this period, a total of $84 \mathrm{ca}-$ rotid arteries (42 patients) received both MDCT angiography and analysis of plaque characteristics by BB MR. Of these 84 carotid arteries, 34 ( 29 patients) demonstrated $>50 \%$ atherosclerotic stenosis. Six carotid arteries (6 patients) were excluded from the study because of the presence of other potential causes for their neurologic symptoms (full occlusion, 3 arteries, and possible dissection, 3 arteries). Twenty-three Japanese patients (all males, mean age $70.6 \pm 6.5$ years) with a total of 28 lesions were finally enrolled in this study (fig. 1).

\section{Definitions of Symptomatic and Asymptomatic Patients}

Enrolled patients were classified to have either (1) a symptomatic lesion with a documented neurologic event (stroke, transient ischemic attack or amaurosis fugax) in a vascular distribution concordant with the affected carotid artery, or (2) an asymptomatic atherosclerotic lesion. Transient ischemic attack and stroke events were defined on the basis of previ- 


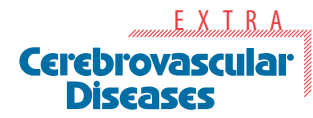

\begin{tabular}{l}
\hline \begin{tabular}{l}
\hline Cerebrovasc Dis Extra 2011;1:54-65 \\
\hline DOI: 10.1159/000328645
\end{tabular} \\
$\begin{array}{l}\text { Published online: May 31, 2011 } \\
\text { www.karger.com/cee }\end{array}$ \\
\hline Miura et al.: Positive Remodeling in the Carotid Artery
\end{tabular}

Table 1. Baseline patient demographics and clinical characteristics (means \pm SD)

\begin{tabular}{llll}
\hline Variables & Symptomatic & Asymptomatic & p value \\
\hline Lesions, $\mathrm{n}$ & 17 & 11 & \\
Age, years & $71.1 \pm 1.1$ & $70.6 \pm 7.8$ & $>0.05$ \\
NASCET, $\%$ & $77.5 \pm 14.5$ & $70.6 \pm 10.0$ & $>0.05$ \\
Risk factors & & & \\
$\quad$ Hypertension & 13 & 8 & $>0.05$ \\
$\quad$ Dyslipidemia & 13 & 7 & $>0.05$ \\
$\quad$ Diabetes & 9 & 5 & $>0.05$ \\
$\quad$ Smoking & 6 & & $>0.05$ \\
\hline
\end{tabular}

ously published criteria $[15,16]$. Amaurosis fugax was defined as acute onset of transient complete or partial monocular loss of vision. The final 28 lesions included 17 symptomatic and 11 asymptomatic lesions (table 1).

\section{Computed Tomography}

MDCT angiography was performed in all study patients using helical acquisition with a 64-detector row CT scanner (SOMATOM Definition; Siemens Medical Solutions, Forchheim, Germany) with two X-ray tubes mounted onto a single gantry at an angle of $90^{\circ}$. The imaging acquisition parameters were as follows: spiral mode 0.33 -second gantry rotation; collimation, $32 \times 0.6 \mathrm{~mm}$; pitch factor, 1.5 ; section thickness $1.0 \mathrm{~mm}$; reconstruction interval, $0.5 \mathrm{~mm}$, and acquisition parameters $120 \mathrm{kVp}$ and $350 \mathrm{~mA}$. A total $50 \mathrm{ml}$ of non-ionized contrast medium, iohexol (Omnipaque 300; Dainichi Sankyo, Tokyo, Japan) or iopamidol (Iopamiron 300; Bayer Schering Pharma, Berlin, Germany), was injected at a flow rate of 3.5 $\mathrm{ml} / \mathrm{s}$, followed by $25 \mathrm{ml}$ of a saline chaser at the same rate as the contrast medium. Optimal timing of MDCT angiography acquisition was determined by an automated bolus-timing program. Images were obtained from the aortic arch to the level of the inferior orbits. The image data were transferred to a computer workstation (Ziostation version 1.17; Amin, Tokyo, Japan) for image post-processing.

Image Analysis

All measurements of luminal stenosis were performed by a single experienced neuroradiologist (K.S.) who was blinded to the clinical information. The degree of luminal stenosis in the carotid arteries was evaluated by image analysis of an axial image and curved multiplanar reconstruction to produce a two-dimensional image showing the cross-sectional profile of a vessel along its length [1] (fig. 2A, C). The degree of stenosis was determined by the neuroradiologist on the basis of these data, following the criteria of the North American Symptomatic Carotid Endarterectomy Trial (NASCET). After identifying the atherosclerotic lesions on axial images, serial cross-sectional images of the carotid arteries were obtained by changing the orientation of the z-axis to analyze the proximal portions of the internal carotid arteries. Using image display settings of window level 250 and width 700, the region of maximum luminal narrowing was visually identified and the outer vessel contour was manually traced to allow calculation of the cross-sectional vessel area (CSA; fig. 2C). In addition, reference CSAs were measured at the nearest proximal and distal segments without atherosclerotic plaques, and the mean values of these were calculated as reference CSAs (fig. 2B, D). On the basis of these numerical values, two values were calculated to assess plaque remodeling of carotid arteries: the plaque remodeling index (RI), which was calcu- 


\section{Cerebrovascular Diseases}

\begin{tabular}{l|l}
\hline Cerebrovasc Dis Extra 2011;1:54-65 \\
\hline DOI: 10.1159/000328645 & $\begin{array}{l}\text { @ 2011 S. Karger AG, Basel } \\
\text { www.karger.com/cee }\end{array}$ \\
Published online: May 31, 2011 &
\end{tabular}

Miura et al.: Positive Remodeling in the Carotid Artery

Fig. 2. MDCT angiography and BB MR analysis. The degree of luminal stenosis in the carotid arteries was evaluated from axial images and curved multiplanar reconstruction following NASCET criteria (A, C). After identifying the atherosclerotic lesions, serial cross-sectional images of the carotid arteries were obtained by altering the $\mathrm{z}$-axis to allow analysis of the nearest distal (B) and proximal portions (D) without atherosclerotic plaque lesions. The outer vessel contour was manually traced to calculate the cross-sectional vessel area in each portion, and a mean reference CSA value was calculated. Plaque remodeling of carotid arteries was assessed using both RI and RR. On MRI, signal intensity of the plaque lesion of interest was calculated relative to the signal intensity to the sternocleidomastoid muscle on T1WI (E). At = Anterior; $\mathrm{P}=$ posterior; $\mathrm{L}=$ left; $\mathrm{R}$ = right.
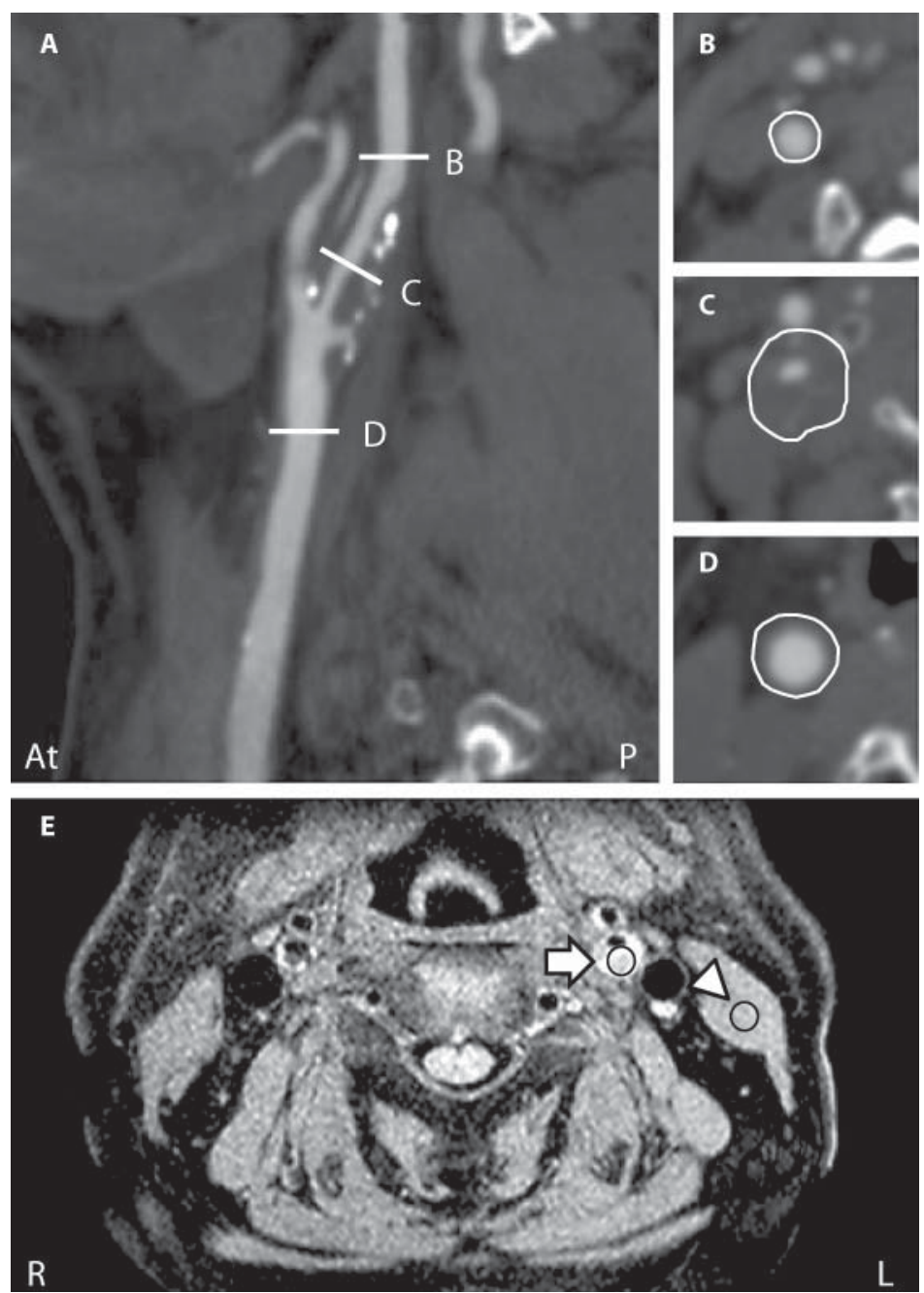

lated as the ratio of CSA at the maximal vessel stenosis (measured from the luminal-intimal boundary to the outer vessel wall) to the mean reference CSA [17], and plaque RR, which was calculated as the ratio of CSA at the maximal vessel stenosis to the reference CSA in the distal portion [18].

$\mathrm{RI}=\mathrm{CSA}$ at the point of maximum stenosis/mean of reference CSA

$\mathrm{RR}=\mathrm{CSA}$ at the point of maximum stenosis/reference CSA at the distal portion

Positive remodeling or negative remodeling was defined on the basis of RI or RR: positive remodeling $\mathrm{RI}>1.0$; negative remodeling $\mathrm{RI}<1.0$; positive remodeling $\mathrm{RR}>1.0$, and negative remodeling $\mathrm{RR}<1.0$.

\section{Magnetic Resonance Imaging}

MRI was performed using a 1.5-tesla whole-body imager (Gyroscan Intra; Philips Medical Systems, Best, The Netherlands). Two types of MRI data were collected for each patient: (1) three-dimensional time of flight (3D-TOF) MR angiography (MRA), and (2) electrocardiogram (ECG)-gated BB images. 3D-TOF MRA was performed using 3D- $\mathrm{T}_{1}$ fast-field echo sequence with an 8-channel SENSE neurovascular coil (5 cases) or Synergy Head/Neck coil 


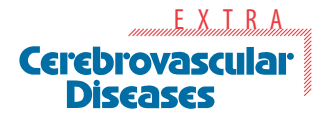

\begin{tabular}{l}
\hline \begin{tabular}{l} 
Cerebrovasc Dis Extra 2011;1:54-65 \\
\hline DOI: 10.1159/000328645
\end{tabular} \\
$\begin{array}{l}\text { Published online: May 31, 2011 } \\
\text { www.karger.com/cee }\end{array}$ \\
\hline Miura et al.: Positive Remodeling in the Carotid Artery
\end{tabular}

(8 cases). Scan parameters were as follows: repetition time (TR) 16-24 ms; echo time (TE) 3.7-6.9 ms; flip angle $18-22^{\circ}$; field of view (FOV) 170-1,200 ms; matrix 256-304 × 174-196, and slice thickness (Thk) 1.2-2.0 mm. BB $\mathrm{T}_{1}$-weighted imaging (T1WI) and $\mathrm{T}_{2}$-weighted imaging (T2WI) were performed using an ECG-gated double inversion recovery two-dimensional turbo spin-echo sequence with 8-channel SENSE neurovascular coil (4 cases) or small-diameter radiofrequency surface coil (2 cases). Parameters for BB T1WI were as follows: TR 750-1,200 ms; TE 14-17 ms; echo train length 7; FOV 160-200 mm; matrix $304 \times$ 222-242, and Thk $3 \mathrm{~mm}$. Parameters for BB T2WI were as follows: TR 1,500-2,400 ms; TE 70-80 ms; echo train length 17; FOV 160-200 mm; matrix 256-304 × 187-241, and Thk 3 $\mathrm{mm}$. Chemical-selective fat saturation was applied to all BB sequences to reduce the signal from subcutaneous fat tissues. Zero-filled Fourier transformation was used to reduce pixel size, which ranged from $0.31 \times 0.31$ to $0.49 \times 0.49 \mathrm{~mm}$, depending on FOV, and to minimize partial-volume artifacts.

The most stenotic lesion was initially identified by 3D-TOF MRA. BB images were subsequently obtained in the transverse plane almost perpendicular to the long axis of the abnormal vessel. Slice levels were centered at the carotid bifurcation on the operative side in each patient. This protocol generated 3-9 image locations per patient examination.

Image Analysis

A manual operator-defined region of interest was drawn for each plaque to calculate the signal intensity relative to the ipsilateral sternocleidomastoid muscle on BB T1WI using the following formula (fig. 2E). Circular regions of interest between $5-10 \mathrm{~mm}^{2}$ were placed on a workstation (Ziostation; by T.M.).

$$
\text { Relative signal intensity }(\mathrm{rSI})=\frac{\text { signal intensity in plaque }}{\text { signal intensity in the sternocleidomastoid muscle }} \text {. }
$$

\section{Histological Grading of Carotid Artery Plaques Obtained by CEA}

Ten samples of lesions obtained by CEA were used to categorize and assess the histologic classification of atherosclerotic plaques. After surgery, the CEA specimens were fixed in 10\% normal formaldehyde and cut into sequential 5-mm blocks, starting from the specimen base (the proximal or common carotid end) towards the bifurcation and beyond until the whole length of the specimen had been cut. Sections from each block were stained with hematoxylin and eosin. Complicated (type VI) plaques were graded using the following criteria: (1) free red blood cells within the intima or media not associated with the blood vessel lumen; (2) organized lamellar plaque or luminal adherent thrombosis (lines of Zahn, platelets, fibrin, red blood cells and white blood cells); (3) hemosiderin-containing macrophages, or (4) surface defects or rupture. On the basis of the above American Heart Association (AHA) criteria, 10 atherosclerotic plaques were classified into either stage VI or not by a single experienced neurosurgeon (H.K.) who was blinded to the clinical information.

\section{Biochemical Markers}

High-sensitivity C-reactive protein (hsCRP), hemoglobin A1C (HbA1C), total cholesterol, low-density lipoprotein cholesterol (LDL-C) and high-density lipoprotein cholesterol (HDL-C) levels were measured as follows: hsCRP by latex agglutination nephelometry; $\mathrm{HbA1C}$ by high-performance liquid chromatography; total cholesterol by enzyme reaction using N-ethyl-N-(2-hydroxy-3-sulfopropyl)-3,5-dimethoxyaniline sodium salt (DAOS method); HDL-C by direct measurement using cholesterol esterase, cholesterol oxidase and peroxidase, and LDL-C was indirectly calculated using the Friedewald formula. In the symptomatic group, data obtained within 7 days after the stroke event were selected. 


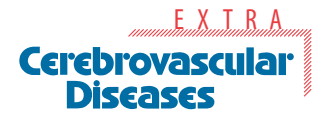

\begin{tabular}{|c|c|}
\hline \multicolumn{2}{|c|}{ Cerebrovasc Dis Extra 2011;1:54-65 } \\
\hline $\begin{array}{l}\text { DOI: 10.1159/000328645 } \\
\text { Published online: May 31, } 2011\end{array}$ & $\begin{array}{l}\text { (c) } 2011 \text { S. Karger AG, Basel } \\
\text { www.karger.com/cee }\end{array}$ \\
\hline
\end{tabular}

Table 2. Radiologic findings (means $\pm \mathrm{SD}$ )

\begin{tabular}{llll}
\hline Variables & Symptomatic & Asymptomatic & p value \\
\hline Lesions, n & 17 & 11 & \\
RI & $1.67 \pm 0.62$ & $1.12 \pm 0.38$ & $<0.05$ \\
RR & $3.55 \pm 1.61$ & $1.90 \pm 0.80$ & $<0.05$ \\
rSI on T1WI & $1.54 \pm 0.26$ & $1.27 \pm 0.35$ & $<0.05$ \\
\hline
\end{tabular}

\section{Statistical Analysis}

All statistical analyses were performed using PASW Statistic 18.0 for Windows (SPSS, Chicago, Ill., USA). All data are given as means \pm SD. Mann-Whitney U tests were used to compare scores between the symptomatic and asymptomatic groups for unpaired samples. Correlations between two factors were analyzed by Spearman's rank correlation. Statistical significance was preset at $\mathrm{p}<0.05$.

\section{Results}

\section{Patient Characteristics}

Table 1 shows the characteristics of the 23 patients with 28 atherosclerotic plaque lesions registered in this study. All patients were male. The average degree of stenosis (NASCET score) was $>70 \%$, suggesting an indication for surgical intervention, such as CAS or CEA. There were no significant differences between the symptomatic and asymptomatic groups regarding age, degree of stenosis or prevalence of stroke risk factors (hypertension, dyslipidemia, diabetes mellitus and smoking).

Remodeling Characteristics in Symptomatic and Asymptomatic Atherosclerotic Plaques

Table 2 shows the RIs, RRs and signal intensities of plaques relative to those of the sternocleidomastoid muscle on BB T1WI (rSI). RI and RR were both significantly higher in symptomatic lesions than in asymptomatic lesions (both $\mathrm{p}<0.05$ ). The rSI on BB T1WI in symptomatic lesions was significantly higher than in asymptomatic lesions, indicating the presence of lipid-rich plaques in symptomatic lesions compared with asymptomatic lesions $(\mathrm{p}<0.05)$.

The correlations between RI, RR and rSI were calculated to elucidate the relationship between remodeling and plaque lipid content. There were significant correlations between both RI and $\mathrm{rSI}(\mathrm{r}=0.41, \mathrm{p}=0.03)$, and between RR and $\mathrm{rSI}(\mathrm{r}=0.50, \mathrm{p}=0.01)$. These results suggest that plaques with positive remodeling in internal carotid arteries contained more lipid than those in arteries with luminal narrowing (fig. 3).

To validate these results, 10 plaque lesions obtained by CEA were selected, and differences in RI, RR and rSI between type VI and non-type VI plaques were calculated. There were significant differences in RI, RR and rSI between the two groups $(p<0.05)$, but no significant differences in age or percent of luminal stenosis. These histologic results confirmed the validity of the imaging results (table 3 ).

\section{Remodeling Characteristics and Biochemical Markers}

No significant differences in the levels of the biochemical markers, hsCRP, HbA1C, total cholesterol, LDL-C and HDL-C, were detected between the symptomatic and asymptomatic groups (table 4). No correlations between RI or RR and each biochemical marker were detected (data not shown). 


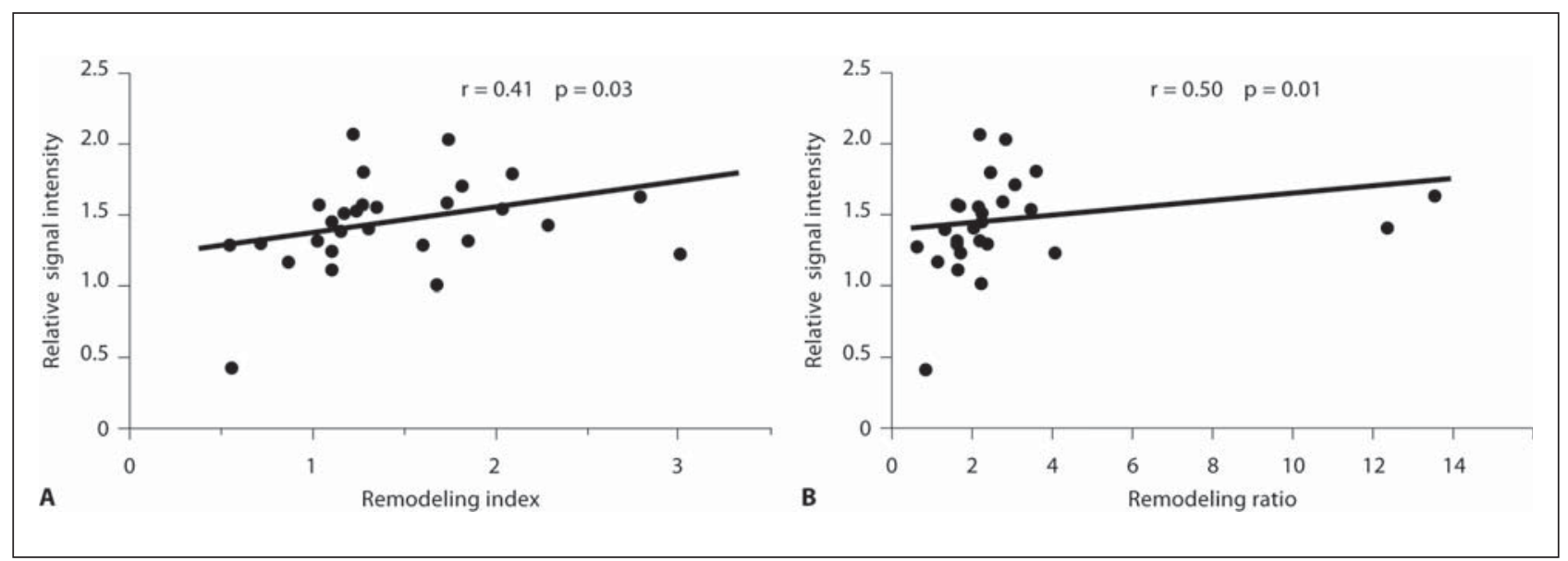

Fig. 3. Correlations between $\mathrm{rSI}$ and $\mathrm{RI}(\mathbf{A}) / \mathrm{RR}(\mathbf{B})$ were calculated, and significant correlations were found between both RI and rSI ( $\mathrm{r}=0.41, \mathrm{p}=0.03)$, and between $\mathrm{RR}$ and $\mathrm{rSI}(\mathrm{r}=0.50, \mathrm{p}=0.01)$.

\section{Discussion}

This study demonstrated three main findings. Firstly, plaques in the carotid artery with positive remodeling were associated with a significantly higher stroke prevalence than plaques with negative remodeling. Secondly, plaques with positive remodeling appeared to have significantly higher lipid contents than those with negative remodeling in both radiologic and histologic analysis. We also demonstrated that levels of biological markers, such as hsCRP, HbA1C, total cholesterol, LDL-C and HDL-C, were not useful for predicting stroke events, even though they have been shown to be significantly associated with coronary events [8].

Extensive vascular remodeling in the coronary circulation may be an indicator of plaque vulnerability to rupture [4]. Vulnerable plaques may contain a large necrotic lipid core with a thin or disrupted fibrous cap, with the potential to cause embolization or thrombosis. A previous report also found that plaques with positive remodeling had significantly larger lipid cores and higher macrophage counts than negatively or less positively remodeled plaques, also indicating increased vulnerability of more extensively remodeled plaques using a combination of functional and morphologic mechanisms [6].

MDCT angiography can clearly depict the various layers constituting the arterial wall. This technique has previously been used as an accurate method of assessing the percent luminal narrowing in the carotid artery [19]. The curved multiplanar reconstruction analysis technique used in the current study has the advantage of being able to evaluate luminal narrowing throughout the carotid artery, making identification of the point of maximum narrowing easier. A previous study proposed two potentially useful parameters for demonstrating the degree of arteriosclerosis in the coronary artery. The plaque RI is calculated as the ratio of CSA at the point of maximal vessel stenosis, measured from the luminalintimal boundary to the outer vessel wall, to the mean reference CSA [17]. The plaque RR is calculated as the ratio of CSA at the point of maximal vessel stenosis to the reference CSA at the distal portion [18]. RR is similar to the use of NASCET criteria to assess the degree of luminal narrowing. RI is less likely to be subject to artificial variation (compared with RR) and might thus represent a more stable and accurate assessment scale. In the current study, we calculated correlations using both measures to exclude any discrepancies 


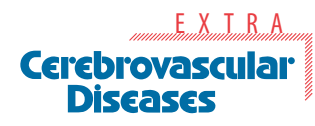

\begin{tabular}{l}
\hline Cerebrovasc Dis Extra 2011;1:54-65 \\
\hline DOI: 10.1159/000328645
\end{tabular}
\begin{tabular}{ll} 
Published online: May 31, 2011 & $\begin{array}{l}\text { @ } 2011 \text { S. Karger AG, Basel } \\
\text { www.karger.com/cee }\end{array}$ \\
\hline Miura et al.: Positive Remodeling in the Carotid Artery
\end{tabular}

Table 3. Comparison of radiologic parameters between type-VI and non-type-VI groups (means \pm SD)

\begin{tabular}{llll}
\hline Variables & Type-VI group & Non-type-VI group & $\mathrm{p}$ value \\
\hline Lesions, $\mathrm{n}$ & 5 & 5 & \\
Age, years & $66.4 \pm 5.32$ & $67.2 \pm 5.26$ & $>0.05$ \\
NASCET, \% & $76.5 \pm 11.7$ & $74.9 \pm 9.5$ & $>0.05$ \\
RI & $1.35 \pm 0.34$ & $0.88 \pm 0.25$ & $<0.05$ \\
RR & $2.29 \pm 0.49$ & $1.30 \pm 0.33$ & $<0.05$ \\
rSI on T1WI & $1.50 \pm 0.15$ & $1.07 \pm 0.38$ & $<0.05$ \\
\hline
\end{tabular}

Table 4. Comparison of biological markers between symptomatic and asymptomatic groups (means \pm SD)

\begin{tabular}{lccc}
\hline Markers & $\begin{array}{l}\text { Symptomatic } \\
(\mathrm{n}=17)\end{array}$ & $\begin{array}{l}\text { Asymptomatic } \\
(\mathrm{n}=11)\end{array}$ & $\mathrm{p}$ value \\
\hline $\mathrm{hsCRP}, \mathrm{mg} / \mathrm{dl}$ & $0.18 \pm 0.21$ & $0.25 \pm 0.30$ & $>0.05$ \\
T-Chol, mg/dl & $180.3 \pm 37.7$ & $165.9 \pm 30.3$ & $>0.05$ \\
HDL-C, mg/dl & $48.3 \pm 13.6$ & $42.0 \pm 11.6$ & $>0.05$ \\
LDL-C, mg/dl & $105.7 \pm 34.2$ & $104.2 \pm 27.0$ & $>0.05$ \\
HbAlc, \% & $6.2 \pm 0.76$ & $7.0 \pm 2.18$ & $>0.05$ \\
\hline
\end{tabular}

T-Chol $=$ Total cholesterol.

associated with the analytical method, and the results suggested that positive RR and RI values were both predictive of stroke events, as in coronary arteries. These results are in accord with those of another recent report, which showed that a positive RR value indicated underlying atherosclerotic plaque vulnerability in carotid arteries using MDCT angiography [9].

A previous study of positive remodeling of the internal carotid artery was limited by the lack of correlations between histologic vessel wall measurements and MDCT values [9]. Complicated and vulnerable plaques are defined by histologic analysis as plaques with surface rupture or intraplaque/intraluminal hemorrhage, indicative of stage VI by histologic AHA criteria [20]. Previous reports demonstrated that T1WI of carotid arteries may be useful for identifying histologically complicated plaques with hemorrhage or thrombus, because the formation of methemoglobin is associated with shortening of $\mathrm{T}_{1}$ in the acute to subacute phase of rupture [21]. Furthermore, new MRI techniques may be able to differentiate between atherosclerotic plaques in terms of the presence of lipid-rich necrotic cores, hemorrhage and calcification [22]. In the current study, the qualitative contents of plaques were estimated using the $\mathrm{BB}$ technique, suppressing the signal from flowing blood, based on pulse sequences designed for vascular imaging [13]. These sequences are ideal for plaque imaging because the conspicuity of the vessel wall is increased when adjacent to a hypointense lumen, in which the echo and repetition times can be varied to optimize visualization of specific plaque components [23]. The ratio of plaque intensity to that of the sternocleidomastoid muscle was calculated to eliminate variations in intensity among images [14]. Our results showed that rSI was higher in symptomatic than in asymptomatic plaques. We also confirmed that rSI correlated significantly with both RI and RR. These results suggest that 


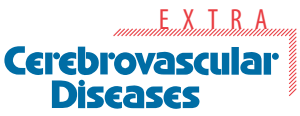

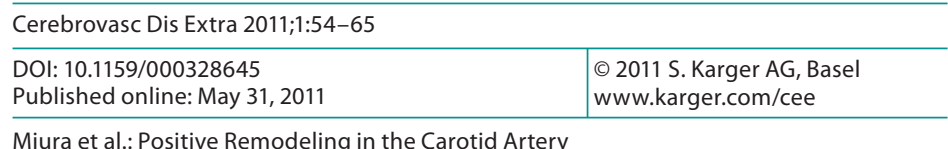

plaques in positively remodeled internal carotid arteries, indicative of type VI stage by AHA criteria, may be more vulnerable to stroke than those in arteries with luminal narrowing. Thus, combined analysis of both RI and RR using MDCT angiography and rSI using BB MRI may be useful for predicting stroke events. We confirmed the validity of this conclusion by histologic analysis of plaques obtained by CEA. The indications for surgical interventions, including CEA and CAS, might be reconsidered on the basis of histologic alterations, represented by RI, RR or rSI, because low-grade stenosis with vulnerable lesions may result in cerebrovascular events [24].

Numerous potential risk factors for the development of atherosclerotic plaques in coronary events have been reported [8]. hsCRP, in particular, has been focused on as an independent risk factor for ischemic stroke in Japanese men [25]. In the current study, we calculated the correlations between the degree of positive remodeling and levels of hsCRP, HbA1C, total cholesterol, LDL-C and HDL-C; however, the results suggested that these markers were of little value in predicting future stroke events.

This study had several potential limitations. First, the retrospective design of the study meant that the parameters being measured could be the results, rather than the causes of the cerebral events. In addition, although the assessed plaques may have been the source of the symptoms, imaging only assessed a representative selection of previously ruptured plaques. These factors imply that it is difficult to draw firm conclusions about the predictive value of remodeling parameters for future stroke events. Secondly, the number of patients assessed in this study was small and further prospective studies with more patients are needed to validate the results of this preliminary study.

\section{Conclusions}

In the current series of patients with significant carotid stenosis, the degree of positive remodeling, represented by both RI and RR, was significantly greater in symptomatic lesions with cerebral ischemic events than in asymptomatic lesions. In both radiologic and histologic analyses, these lesions were confirmed as vulnerable plaques with underlying surface rupture or intraplaque/intraluminal hemorrhage, indicative of stage VI according to histologic AHA criteria. These results suggest that the combined analysis of RR, RI and rSI might help to predict future stroke events.

\section{Disclosure Statement}

The authors have no conflicts of interest to disclose.

\section{References}

1 Beneficial effect of carotid endarterectomy in symptomatic patients with high-grade carotid stenosis. North American Symptomatic Carotid Endarterectomy Trial Collaborators. N Engl J Med 1991;325: 445-453.

-2 Barnett HJ, Taylor DW, Eliasziw M, Fox AJ, Ferguson GG, Haynes RB, Rankin RN, Clagett GP, Hachinski VC, Sackett DL, Thorpe KE, Meldrum HE, Spemce JD: Benefit of carotid endarterectomy in patients with symptomatic moderate or severe stenosis. North American Symptomatic Carotid Endarterectomy Trial Collaborators. N Engl J Med 1998;339:1415-1425. 


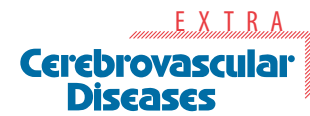

Cerebrovasc Dis Extra 2011;1:54-65

DOI: 10.1159/000328645

Published online: May 31, 2011

Miura et al.: Positive Remodeling in the Carotid Artery (c) 2011 S. Karger AG, Basel

www.karger.com/cee

-3 Yadav JS, Wholey MH, Kuntz RE, Fayad P, Katzen BT, Mishkel GJ, Balwa TK, Whitlow P, Strickman NE, Jaf MR, Popma JJ, Snead DB, Cutlip DE, Firth BG, Ouriel K, Stenting and Angioplasty with Protection in Patients at High Risk for Endarterectomy Investigators: Protected carotid-artery stenting versus endarterectomy in high-risk patients. N Engl J Med 2004;351:1493-1501.

4 Glagov S, Weisenberg E, Zarins CK, Stankunavicius R, Kolettis GJ: Compensatory enlargement of human atherosclerotic coronary arteries. N Engl J Med 1987;316:1371-1375.

-5 Schoenhagen P, Ziada KM, Kapadia SR, Crowe TD, Nissen SE, Tuzcu EM: Extent and direction of arterial remodeling in stable versus unstable coronary syndromes: an intravascular ultrasound study. Circulation 2000;101:598-603.

-6 Varnava AM, Mills PG, Davies MJ: Relationship between coronary artery remodeling and plaque vulnerability. Circulation 2002;105:939-943.

7 Kiechl S, Willeit J: The natural course of atherosclerosis. Part I: incidence and progression. Arterioscler Thromb Vasc Biol 1999;19:1484-1490.

-8 Naghavi M, Libby P, Falk E, Casscells SW, Litovsky S, Rumberger J, Badimon JJ, Stefanadis C, Moreno P, Pasterkamp G, Fayad Z, Stone PH, Waxman S, Raggi P, Madjid M, Zarrabi A, Burke A, Yuan C, Fitzgerald PJ, Siscovick DS, de Korte CL, Aikawa M, Juhani Airaksinen KE, Assmann G, Becker CR, Chesebro JH, Farb A, Galis ZS, Jackson C, Jang IK, Koening W, Lodder RA, March K, Demirovic J, Navab M, Priori SG, Rekhter MD, Bahr R, Grundy SM, Mehran R, Colombo A, Boerwinkle E, Ballantyne C, Insull W Jr, Schwartz RS, Vogel R, Serruys PW, Hansson GK, Faxon DP, Kaul S, Drexler H, Greenland P, Muller JE, Virmani R, Ridker PM, Zipes DP, Shah PK, Willerson JT: From vulnerable plaque to vulnerable patient: a call for new definitions and risk assessment strategies. Part I. Circulation 2003;108:1664-1672.

-9 Hardie AD, Kramer CM, Raghavan P, Baskurt E, Nandalur KR: The impact of expansive arterial remodeling on clinical presentation in carotid artery disease: a multidetector CT angiography study. AJNR Am J Neuroradiol 2007;28:1067-1070.

-10 Saba L, Sanfilippo R, Pirisi R, Pascalis L, Montisci R, Mallarini G: Multidetector-row CT angiography in the study of atherosclerotic carotid arteries. Neuroradiology 2007;49:623-637.

-11 Coombs BD, Rapp JH, Ursell PC, Reilly LM, Saloner D: Structure of plaque at carotid bifurcation: high-resolution MRI with histological correlation. Stroke 2001;32:2516-2521.

-12 Gortler M, Goldmann A, Mohr W, Widder B: Tissue characterisation of atherosclerotic carotid plaques by MRI. Neuroradiology 1995;37:631-635.

-13 Simonetti OP, Finn JP, White RD, Laub G, Henry DA: 'Black blood' T2-weighted inversion-recovery MR imaging of the heart. Radiology 1996;199:49-57.

-14 Yoshida K, Narumi O, Chin M, Inoue K, Tabuchi T, Oda K, Nagayama M, Egawa N, Hojo M, Goto Y, Watanabe Y, Yamagata S: Characterization of carotid atherosclerosis and detection of soft plaque with use of black-blood MR imaging. AJNR Am J Neuroradiol 2008;29:868-874.

-15 Albers GW, Caplan LR, Easton JD, Fayad PB, Mohr JP, Saver JL, Sherman DG, TIA Working Group: Transient ischemic attack - proposal for a new definition. N Engl J Med 2002;347:1713-1716.

-16 Inzitari D, Eliasziw M, Gates P, Sharpe BL, Chan RK, Meldrum HE, Barnett HJ: The causes and risk of stroke in patients with asymptomatic internal-carotid-artery stenosis. North American Symptomatic Carotid Endarterectomy Trial Collaborators. N Engl J Med 2000;342:1693-1700.

- 17 Imazeki T, Sato Y, Inoue F, Anazawa T, Tani S, Matsumoto N, Takayama T, Uchiyama T, Saito S: Evaluation of coronary artery remodeling in patients with acute coronary syndrome and stable angina by multislice computed tomography. Circ J 2004;68:1045-1050.

- 18 Achenbach S, Ropers D, Hoffmann U, MacNeill B, Baum U, Pohle K, Brady TJ, Pomerantsev E, Ludwig J, Flachskampf FA, Wicky S, Jang IK, Daniel WG: Assessment of coronary remodeling in stenotic and nonstenotic coronary atherosclerotic lesions by multidetector spiral computed tomography. J Am Coll Cardiol 2004;43:842-847.

-19 Randoux B, Marro B, Koskas F, Duyme M, Sahel M, Zouaoui A, Marsault C: Carotid artery stenosis: prospective comparison of $\mathrm{CT}$, three-dimensional gadolinium-enhanced $\mathrm{MR}$, and conventional angiography. Radiology 2001;220:179-185.

-20 Stary HC, Chandler AB, Dinsmore RE, Fuster V, Glagov S, Insull W Jr, Rosenfeld ME, Schwartz CJ, Wagner WD, Wissler RW: A definition of advanced types of atherosclerotic lesions and a histological classification of atherosclerosis. A report from the Committee on Vascular Lesions of the Council on Arteriosclerosis, American Heart Association. Circulation 1995;92:1355-1374. 
-21 Moody AR, Murphy RE, Morgan PS, Martel AL, Delay GS, Allder S, MacSweeney ST, Tennant WG, Gladman J, Lowe J, Hunt BJ: Characterization of complicated carotid plaque with magnetic resonance direct thrombus imaging in patients with cerebral ischemia. Circulation 2003;107: 3047-3052.

-22 Yuan C, Kerwin WS, Yarnykh VL, Cai J, Saam T, Chu B, Takaya N, Ferguson MS, Underhill H, Xu D, Liu F, Hatsukami TS: MRI of atherosclerosis in clinical trials. NMR Biomed 2006;19:636-654.

-23 Chu B, Kampschulte A, Ferguson MS, Kerwin WS, Yarnykh VL, O'Brien KD, Polissar NL, Hatsukami TS, Yuan C: Hemorrhage in the atherosclerotic carotid plaque: a high-resolution MRI study. Stroke 2004;35:1079-1084.

24 Virmani R, Ladich ER, Burke AP, Kolodgie FD: Histopathology of carotid atherosclerotic disease. Neurosurgery 2006;59(5 suppl 3):S219-S227, discussion S3-S13.

-25 Wakugawa Y, Kiyohara Y, Tanizaki Y, Kubo M, Ninomiya T, Hata J, Doi Y, Okubo K, Oishi Y, Shikata K, Yonemoto K, Maebuchi D, Ibayashi S, Iida M: C-reactive protein and risk of first-ever ischemic and hemorrhagic stroke in a general Japanese population: the Hisayama Study. Stroke 2006;37: $27-32$. 